\title{
Chromosomal characteristics of a Brazilian whip spider (Amblypygi) and evolutionary relationships with other arachnid orders
}

\author{
E. Paula-Neto ${ }^{1}$, D. Araujo ${ }^{2}$, L.S. Carvalho ${ }^{3}$, D.M. Cella ${ }^{1}$ and \\ M.C. Schneider ${ }^{4}$ \\ ${ }^{1}$ Departamento de Biologia, Universidade Estadual Paulista, \\ Rio Claro, SP, Brasil \\ ${ }^{2}$ Setor de Biologia Geral, Centro de Ciências Biológicas e da Saúde, \\ Universidade Federal de Mato Grosso do Sul, Campo Grande, MS, Brasil \\ ${ }^{3}$ Universidade Federal do Piauí, Campus Amílcar Ferreira Sobral, \\ Floriano, PI, Brasil \\ ${ }^{4}$ Universidade Federal de São Paulo, Diadema, SP, Brasil
}

Corresponding author: M.C. Schneider

E-mail: marielle.unifesp@gmail.com

Genet. Mol. Res. 12 (3): 3726-3734 (2013)

Received January 20, 2013

Accepted August 17, 2013

Published September 19, 2013

DOI http://dx.doi.org/10.4238/2013.September.19.3

\begin{abstract}
We analyzed mitotic and meiotic cells of a Brazilian amblypygid, Heterophrynus longicornis, using conventional and molecular cytogenetic techniques (Giemsa staining, C-banding, AgNOR, and FISH with rDNA probe). This is the first study that focuses solely on amblypygid chromosomes; it was undertaken to add data on cytogenetic knowledge of this group and contribute to the understanding of chromosome evolution in the Arachnida. We found $2 \mathrm{n}=66$ for male and female individuals, monocentric chromosomes, and absence of morphologically differentiated sex chromosomes. C-banding showed heterochromatin in the pericentromeric region of most chromosomes. Mitotic and meiotic nuclei submitted to
\end{abstract}


silver impregnation and FISH revealed, respectively, Ag-NORs and ribosomal genes in the terminal region of two chromosome pairs. Most chromosome features that we observed in H. longicornis are shared with species of other arachnid orders; however, the absence of morphologically differentiated sex chromosomes in amblypygid contrasts with the remarkable variety of sex chromosome systems recorded for the Araneae. Consequently, we conclude that analysis of species of the Tetrapulmonata clade is useful for understanding the trends of sex chromosome evolution in this arachnid group.

Key words: Chromosome evolution; Diploid number; Karyotype; Heterophrynus longicornis; Sex chromosome system

\section{INTRODUCTION}

The Amblypygi are among the less diverse groups of the class Arachnida, including roughly 161 species, which are grouped into two suborders, Paleoamblypygi and Euamblypygi, and five families (Weygoldt, 1996; Harvey, 2002). The first amblypygid fossil records date back to the Carboniferous period and were found in the Northern Hemisphere; however, before the continental drift, the amblypygid underwent radiation and nowadays different groups of species seem to occur in distinct continents (Weygoldt, 1996). The Amblypygi species show a tropical and subtropical distribution, inhabiting especially rainforests (Harvey, 2002).

The suborder Paleoamblypygi is monotypic and includes a single species of Paracharontidae, which has a restricted distribution, occurring in termite nests in Guinea-Bissau. The other four families are included in the suborder Euamblypygi. Charinidae is the most cosmopolitan within Amblypygi, with circumtropical distribution, while Charontidae is endemic to Australasia. Phrynichidae ranges from Africa to Southeast Asia and a single genus is recorded in Brazil. The Phrynidae are diversified throughout the Americas, but it can show a wide distribution, considering the records in Indonesia (Harvey, 2002).

In the latest phylogenetic proposal of the arachnid orders, which was based on morphological characters, the Amblypygi was considered sister-group to Uropygi (= Thelyphoni$\mathrm{da}+$ Schizomida). These two orders constitute the clade Pedipalpi which, considering only the extant orders, is the sister-group of Araneae, forming the clade Tetrapulmonata (Shultz, 2007).

Cytogenetically, no Amblypygi species have been characterized concerning chromosome morphology, type of sex chromosome system, chromosomal behavior during meiosis, and distribution of constitutive heterochromatin and nucleolar organizer regions (NORs). In a study on the distribution of the (TTAGG) telomere sequence in arthropod species, Vítková et al. (2005) recorded, for the first time, the diploid number in one amblypygid (Phrynichidae), 2n $\widehat{O}^{\lambda}=70$ in Damon medius (Herbst, 1797). In an effort to add data to our cytogenetic knowledge of the amblypygids and to contribute to the understanding of chromosome evolution in Arachnida, the present study was the first exclusively focused on Amblypygi cytogenetics with the aim of investigating the mitotic and meiotic chromosomes of Heterophrynus longicornis (Butler, 1873) (Phrynidae) using conventional (Giemsa staining) and differential techniques (C-banding, silver impregnation, fluorescence in situ hybridization (FISH) with rDNA probe). 


\section{MATERIAL AND METHODS}

The sample of $H$. longicornis analyzed in this work included eight individuals: two males and one female from Floresta Nacional de Palmares - Altos $\left(05^{\circ} 03^{\prime} \mathrm{S}, 43^{\circ} 35^{\prime} \mathrm{W}\right)$, one male from Castelo do Piauí $\left(05^{\circ} 14^{\prime} \mathrm{S}, 41^{\circ} 41^{\prime} \mathrm{W}\right)$, and one female from Teresina $\left(05^{\circ} 05^{\prime} \mathrm{S}, 42^{\circ} 48^{\prime} \mathrm{W}\right)$, State of Piauí, Brazil, and three males from Serra da Ibiapaba, Ubajara $\left(03^{\circ} 49^{\prime} \mathrm{S}, 40^{\circ} 59^{\prime} \mathrm{W}\right)$, State of Ceará, Brazil. The vouchers were deposited in the arachnological collection of the Natural History Collection of the Universidade Federal do Piauí, Floriano, Piauí, Brazil (CHNUFPI; curator L.S. Carvalho). The chromosome preparations were obtained from male and female individuals and stained with Giemsa, following the procedure described by Araujo et al. (2008). To identify the constitutive heterochromatin regions the chromosomes were C-banded (Sumner, 1972) and subsequently stained with 4'-6-diamidino-2-phenylindole (DAPI). Chromosome carriers of active nucleolar organizer regions (Ag-NORs) and ribosomal genes (45S) were revealed using silver nitrate impregnation (Howell and Black, 1980) and FISH with a pDm 238 rDNA probe, respectively. Probes were labeled with digoxigenin by nick translation and detected with rhodamine-conjugated anti-digoxigenin antibody, according to Pinkel et al. (1986) with modifications described by Silva et al. (2012); chromosome spreads were counterstained with DAPI and mounted with antifade. The images of the gonadal cells were captured using an Olympus BX51 light microscope, coupled to an Olympus DP71 digital camera, and the DP Controller software. The chromosomes were measured using the Image J software (Image Processing and Analysis in Java), developed by Research Services Branch of the US National Institute of Mental Health and morphologically classified following the nomenclature proposed by Levan et al. (1964).

\section{RESULTS}

Giemsa-stained mitotic metaphase cells of $H$. longicornis showed $2 \mathrm{n}=66$ for male and female, including submetacentric (pairs 1-2, 21), metacentric (pairs 3-5, 7-15, 18-20, 22$23,26-30,32-33$ ), and subtelocentric (pairs 6, 16-17, 24-25, 31) chromosomes. Although the chromosomes gradually decreased in size, pairs 1 to 5 were classified as the largest ones of the complement (Figure 1). No heteromorphic chromosome pair was observed in a total of 133 gonadal cells of all specimens examined. Additionally, the comparative analysis between male and female karyotypes did not reveal any chromosomal difference that could be attributed to the presence of morphologically differentiated sex chromosomes.

Pachytene spermatocytes exhibited 33 well-paired bivalents. In some cells, most bivalents showed some markedly condensed and stained chromatin blocks, which probably correspond to a particular type of chromatin (Figure 2A). Diplotene cells exhibited 33 isopycnotic bivalents with one interstitial or terminal chiasma; but, in early diplotene nuclei, up to six bivalents showed two chiasmata, occurring in the terminal and/or interstitial region of the chromosomes (Figure 2B and C). Additionally, less-condensed and less-stained chromatin was found in the subterminal region of one large and one medium-sized bivalent. All metaphase II cells showed $n=33$, suggesting reductional behavior and regular segregation of all chromosomes during anaphase I (Figure 2D).

C-banded mitotic and meiotic cells of H. longicornis revealed constitutive heterochromatin in the pericentromeric region of most chromosomes. Similar results were also observed in cells analyzed by FISH and observed with an appropriate filter for DAPI fluorescence (Figure $3 \mathrm{~A}$ ). Despite that the results obtained with silver impregnation were of low quality, the 
mitotic nuclei revealed Ag-NORs on terminal region of two metacentric chromosome pairs of large and medium size; however, the number of active NORs varied from one to three in the sample of cells investigated (Figure 3B and C). Spermatocytes subjected to FISH confirmed that in this species four chromosomes are carriers of $45 \mathrm{~S}$ ribosomal genes (Figure 3D).

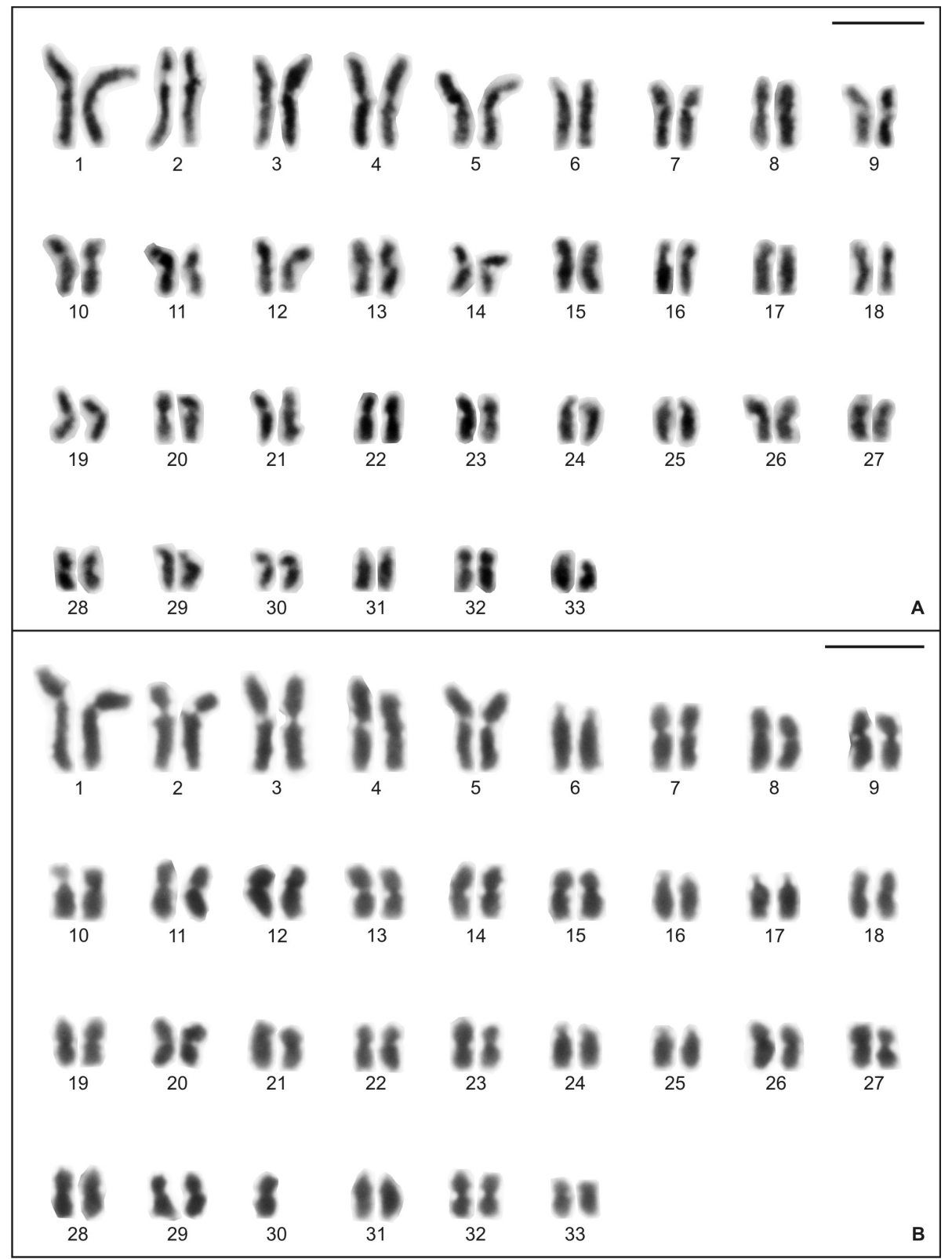

Figure 1. Karyotypes of Heterophrynus longicornis stained with Giemsa. A. Male, $2 \mathrm{n}=66$. B. Female with 65 chromosomes, lacking one chromosomal element of pair 30. Scale bar $=10 \mu \mathrm{m}$. 


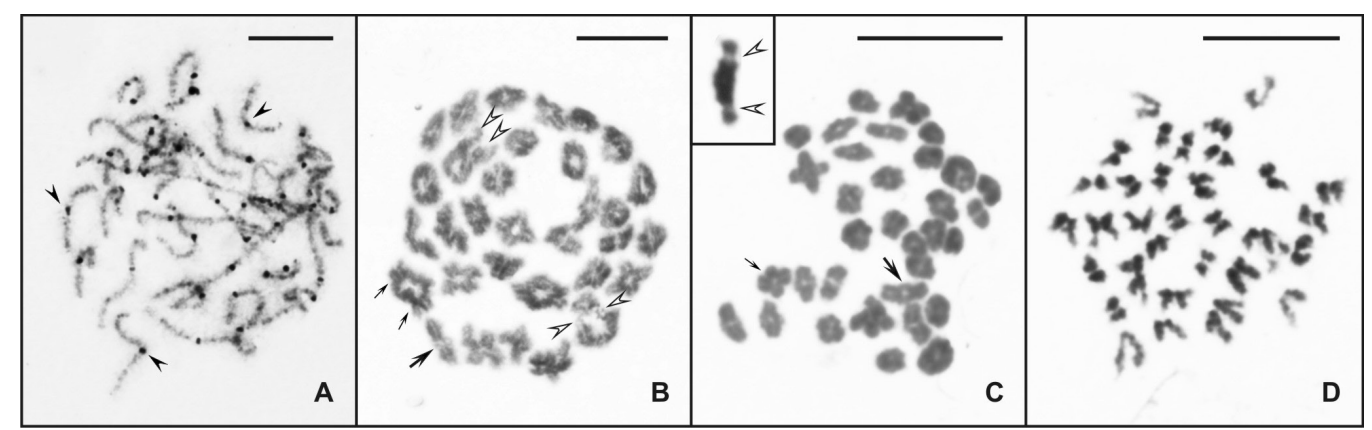

Figure 2. Testicular cells of Heterophrynus longicornis stained with Giemsa. A. Pachytene with 33 bivalents showing deeply stained blocks (arrowhead) in some bivalents. B. and C. Diplotene and diakinesis, respectively, $2 \mathrm{n}$ $=33 \mathrm{II}$. Large arrows = terminal chiasma; small arrows = interstitial chiasma; empty arrowheads = less condensed chromosomal region. The detail in $\mathrm{C}$ shows the less condensed subterminal regions of one bivalent (empty arrowheads). D. Metaphase II with $\mathrm{n}=33$. Scale bar $=10 \mu \mathrm{m}$.

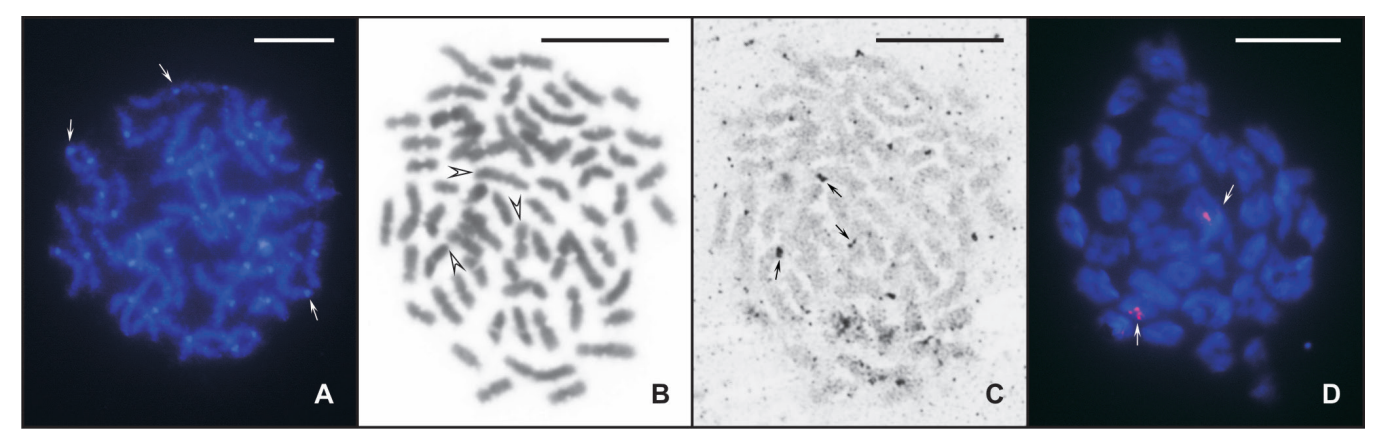

Figure 3. Spermatocytes of Heterophrynus longicornis after FISH (A and D), Giemsa staining (B), and silver impregnation (C). A. Pachytene observed with a filter for DAPI fluorescence revealing heterochromatin in the pericentromeric region of most bivalents (arrows). B. Mitotic metaphase, $2 n=66$. Empty arrowheads $=$ chromosomes carriers of NORs. C. The same cell shown in B, revealing Ag-NORs (arrows) on terminal region of three chromosomes. D. Diplotene, with 33 bivalents, exhibiting ribosomal clusters in two bivalents (arrows). Scale bar $=10 \mu \mathrm{m}$.

\section{DISCUSSION}

The diploid number herein observed in H. longicornis is in close proximity to the $2 \mathrm{n}$ $=70$ observed in $D$. medius by Vítková et al. (2005), the only Amblypygi species with data on the chromosome number. It is interesting to note that $H$. longicornis and D. medius belong to different groups, Phrynidae and Phrynichidae, respectively. Additionally, these two families are considered sister-groups (Phrynoidea superfamily) and derived within the Euamblypygi suborder (Weygoldt, 1996). Thus, high chromosome numbers could constitute a shared characteristic within species of Phrynoidea. However, this is a presumption that can be confirmed only after the analyses of other Amblypygi species.

The cytogenetic information of Uropygi, the sister-group of Amblypygi, revealed diploid number varying from $2 \mathrm{n}=12$ to $2 \mathrm{n}=49$ (Warren, 1939; Makino, 1956; Kasturi Bai and 
Parthasarathy, 1957). Furthermore, among the Tetrapulmonata, high diploid numbers were recorded in basal groups of Araneae $(2 n= \pm 96$ in Mesothelae). In certain other groups of Arachnida, for instance, high chromosome numbers were recorded in derivative groups of all Scorpiones $(2 \mathrm{n}=56-175$ in Urodacidae $)$ and Pseudoscorpiones $(2 \mathrm{n}=61-73$ in Chernetidae $)$ (Suzuki, 1954; Shanahan, 1989; Štáhlavský et al., 2005). Considering this karyotype information, it is possible to suggest that the evolution of the diploid number in the distinct arachnid orders certainly evolved independently to an increase or decrease in chromosome number.

The absence of morphologically differentiated sex chromosomes (i.e., homomorphic) is not an exclusive feature of the Amblypygi species investigated here, but it has also been recorded in all scorpions and in most harvestmen cytogenetically characterized (Schneider et al., 2008, 2009a,b). Král et al. (2008) demonstrated the absence of morphologically differentiated sex chromosomes in Palpigradi species, an arachnid order with numerous primitive characters, and proposed that this condition could constitute an ancestral state for Arachnida. The data obtained in the present work indicate the occurrence of homomorphic sex chromosomes in H. longicornis. Among the Arachnida orders that exhibited identified sex chromosomes, the males were always the heterogametic sex, with the exception of one species of Opiliones, which showed the ZZ/ ZW sex chromosome system (Tsurusaki and Cokendolpher, 1990). In H. longicornis, considering that no morphological differentiation was observed on chromosomes, it is not possible to distinguish between a male $(\mathrm{XY} / \mathrm{XX})$ or female $(\mathrm{ZZ} / \mathrm{ZW})$ heterogamety, because $\mathrm{XY}$ and $\mathrm{ZW}$ homomorphic sex chromosomes have already been described in many groups of animals. In the female of birds, some species possess heteromorphic and others homomorphic ZW sex chromosomes (Handley et al., 2004). The same is true for some male heterogametic mammals, in which some species exhibit heteromorphic and others homomorphic XY sex chromosomes (Ellegren, 2011). Additionally, these authors mentioned that the undifferentiated condition of the sex chromosomes is ancestral and that progressive rearrangements produce at each step more heteromorphic XY and ZW sex chromosomes, forming different "evolutionary strata". Král (2007) had already proposed the origin of neoX and neoY chromosomes from a homomorphic sex chromosome pair (called proto- $X$ and proto- $Y$ chromosomes) in a spider species.

The occurrence of chiasmate meiosis is a common feature for most arachnid groups, as also found for the amblypygid H. longicornis studied in the present work. Until now, the lack of recombination in male meiosis seems to be exclusive for Scorpiones species (Schneider et al., 2009a,b); in other groups, the chromosome association lacking chiasma occurs sporadically, e.g., in certain families of Araneae and Pseudoscorpiones (Rodríguez-Gil et al., 2002; Štáhlavský and Král, 2004). The sporadic occurrence of an achiasmate mode of meiosis in some arachnid orders indicates that the absence of recombination certainly has a secondary origin for these species. Additionally, these data corroborate the proposition of John (1990) that achiasmate meiosis evolved many times within the eukaryote lineage as a whole.

The analysis of mitotic and meiotic cells of $H$. longicornis submitted to C-banding was useful not only to establish for the first time the distribution of constitutive heterochromatin in the chromosomes of an Amplypygi species, but also to confirm the absence of heteromorphic elements, which could be indicative that in H. longicornis the sex chromosomes are in an early stage of differentiation. In distinct organisms, the unequal accumulation of constitutive heterochromatin is usually associated with the process of evolution of the sex chromosomes (Steinemann and Steinemann, 1998).

The scarce knowledge with respect to the cytogenetics of Arachnida is even more re- 
markable when specific chromosome regions are considered. The number and location of NORs were only established, for example, in approximately 30 species of Araneae (Král et al., 2006; Král, 2007; Oliveira et al., 2007; Rodríguez-Gil et al., 2007; Araujo et al., 2008; Stávale et al., 2010, 2011; Dolejš et al., 2011; Král et al., 2011), 17 species of Scorpiones (Schneider et al., 2009a,b; Schneider and Cella, 2010), 3 species of Opiliones (Gorlov and Tsurusaki, 2000; Oliveira et al., 2006; Schneider et al., 2008; Mattos et al., 2013), and two species of Palpigradi (Král et al., 2008). In almost all these species, the NORs were only identified through the use of silver impregnation; however, in an overview of the NOR distribution in Coleoptera, Schneider et al. (2007) showed that the results were usually coincident when the chromosomes were examined with both silver impregnation and FISH technique. Therefore, despite that the NORs data did not correspond to $1 \%$ of all Arachnida species taxonomically described, NORs located on the terminal region of one or two chromosome pairs seem to be widespread in representatives of this group. The results obtained in $H$. longicornis with silver impregnation and FISH using a rDNA probe were in agreement with the pattern of NORs found in most arachnid species, indicating that this distribution of NORs could represent a common condition for the group.

The results obtained in the present work revealed the absence of morphologically differentiated sex chromosomes in one amblypygid. Nevertheless, in groups phylogenetically related to Amblypygi, the occurrence of heteromorphic sex chromosomes has been reported. In Uropygi, the $\mathrm{XY} / \mathrm{XX}$ and $\mathrm{X} 0 / \mathrm{XX}$ sex chromosome systems were observed in species of the genus Thelyphonus, while in Araneae, a remarkable diversity of simple and multiple sex chromosome systems, including approximately 10 different types of system, was recorded in the 676 species studied (Araujo et al., 2012). Thus, the chromosomal investigation of a high diversity of Amblypygi species as well as other pedipalpids (Thelyphonida and Schizomida) offers an excellent opportunity to deepen our knowledge about chromosome diversity and to study the trends of sex chromosome evolution in the Tetrapulmonata arachnids.

\section{ACKNOWLEDGMENTS}

Research supported by Conselho Nacional de Desenvolvimento Científico e Tecnológico (CNPq, \#478630/2010-7) and Fundação de Amparo à Pesquisa do Estado de São Paulo (FAPESP, \#2010/14193-7). This study is also part of "Programa de Pesquisas em Biodiversidade do Semiárido - PPBio Semiárido" (CNPq \#558317/2009-0). Collecting permits were issued by Instituto Brasileiro do Meio Ambiente e dos Recursos Naturais Renováveis [IBAMA, \#25252 (to L.S. Carvalho) and \#25472 (to M.C. Schneider)].

\section{REFERENCES}

Araujo D, Rheims CA, Brescovit AD and Cella DM (2008). Extreme degree of chromosome number variability in species of the spider genus Scytodes (Araneae, Haplogynae, Scytodidae). J. Zool. Syst. Evol. Res. 46: 89-95.

Araujo D, Schneider MC, Paula-Neto E and Cella DM (2012). Sex Chromosomes and Meiosis in Spiders: A Review. In: Meiosis - Molecular Mechanisms and Cytogenetic Diversity (Swan A, ed.). InTech, Croatia, 87-108. Available at [http://www.intechopen.com/books/meiosis-molecular-mechanisms-and-cytogenetic-diversity/sex-chromosomesand-meiosis-of-spiders-a-review]. Accessed June 12, 2012.

Dolejš P, Kořínková T, Musilová J, Opatova V, et al. (2011). Karyotypes of central European spiders of the genera Arctosa, Tricca, and Xerolycosa (Araneae: Lycosidae). Eur. J. Entomol. 108: 1-16.

Ellegren H (2011). Sex-chromosome evolution: recent progress and the influence of male and female heterogamety. Nat. Rev. Genet. 12: 157-166. 
Gorlov IP and Tsurusaki N (2000). Morphology and meiotic/mitotic behavior of B cromosomes in a Japanese harvestman, Metagagrella tenuipes (Arachnida: Opiliones): no evidence for B accumulation mechanisms. Zool. Sci. 17: 349-355.

Handley LJ, Ceplitis H and Ellegren H (2004). Evolutionary strata on the chicken Z chromosome: implications for sex chromosome evolution. Genetics 167: 367-376.

Harvey MS (2002). The neglected cousins: What do we know about the smaller arachnid orders? J. Arachnol. 30: 357-372.

Howell WM and Black DA (1980). Controlled silver-staining of nucleolus organizer regions with a protective colloidal developer: a 1-step method. Experientia 36: 1014-1015.

John B (1990). Meiosis. Cambridge University Press, New York.

Kasturi Bai AR and Parthasarathy MD (1957). The chromosomes of Thelyphonus indicus Stoliczka. Proc. Nat. Inst. Sci. India Part B 24: 19-22.

Král J (2007). Evolution of multiple sex chromosomes in the spider genus Malthonica (Araneae: Agelenidae) indicates unique structure of the spider sex chromosome systems. Chromosome Res. 15: 863-879.

Král J, Musilová J, Štáhlavský F, Rezác M, et al. (2006). Evolution of the karyotype and sex chromosome systems in basal clades of araneomorph spiders (Araneae: Araneomorphae). Chromosome Res. 14: 859-880.

Král J, Kovác L, Štáhlavský F, Lonský P, et al. (2008). The first karyotype study in palpigrades, a primitive order of arachnids (Arachnida: Palpigradi). Genetica 134: 79-87.

Král J, Koř́nková T, Forman M and Krkavcová L (2011). Insights into the meiotic behavior and evolution of multiple sex chromosome systems in spiders. Cytogenet. Genome Res. 133: 43-66.

Levan A, Fredga K and Sandberg AA (1964). Nomenclature for centromeric position on chromosomes. Hereditas 52: 201-220.

Makino S (1956). A Review of the Chromosome Numbers in Animals. Hokuryukan, Tokyo.

Mattos VF, Cella DM, Carvalho LS, Candido DM, et al. (2013). High chromosome variability and the presence of multivalent associations in buthid scorpions. Chromosome Res. 21: 121-136.

Oliveira RM, Zacaro AA, Gnaspini P and Cella DM (2006). Cytogenetics of three Brazilian Goniosoma species: A new record for diploid number in Laniatores (Opiliones, Gonyleptidae, Goniosomatinae). J. Arachnol. 34: 435-443.

Oliveira RM, de Jesus AC, Brescovit AD and Cella DM (2007). Chromosomes of Crossopriza lyoni (Blackwall 1867), intraindividual numerical chromosome variation in Physocyclus globosus (Taczanowski 1874), and the distribution pattern of NORs (Araneomorphae, Haplogynae, Pholcidae). J. Arachnol. 35: 293-306.

Pinkel D, Straume T and Gray JW (1986). Cytogenetic analysis using quantitative, high-sensitivity, fluorescence hybridization. Proc. Natl. Acad. Sci. U. S. A. 83: 2934-2938.

Rodríguez-Gil SG, Mola LM, Papeschi AG and Scioscia CL (2002). Cytogenetic heterogeneity in common Haplogyne spiders from Argentina (Arachnida, Araneae). J. Arachnol. 30: 47-56.

Rodríguez-Gil SG, Merani MS, Scioscia CL and Mola LM (2007). Cytogenetics in three species of Polybetes Simon 1897 from Argentina (Araneae, Sparassidae) I. Karyotype and chromosome banding pattern. J. Arachnol. 35: 227-237.

Schneider MC and Cella DM (2010). Karyotype conservation in 2 populations of the parthenogenetic scorpion Tityus serrulatus (Buthidae): rDNA and its associated heterochromatin are concentrated on only one chromosome. J. Hered. 101: 491-496.

Schneider MC, Rosa SP, Almeida MC, Costa C, et al. (2007). Chromosomal similarities and differences among four Neotropical Elateridae (Conoderini and Pyrophorini) and other related species, with comments on the NOR patterns in Coleoptera. J. Zool. Syst. Evol. Res. 45: 308-316.

Schneider MC, Zacaro AA, Oliveira RM, Ganspini P, et al. (2008). Conventional and ultrastructural analyses of the chromosomes of Discocyrtus pectinifemur (Opiliones, Laniatores, Gonyleptidae). J. Zool. Syst. Evol. Res. 47: 203207.

Schneider MC, Zacaro AA, Pinto-da-Rocha R, Candido DM, et al. (2009a). A comparative cytogenetic analysis of 2 Bothriuridae species and overview of the chromosome data of Scorpiones. J. Hered. 100: 545-555.

Schneider MC, Zacaro AA, Pinto-da-Rocha R, Candido DM, et al. (2009b). Complex meiotic configuration of the holocentric chromosomes: the intriguing case of the scorpion Tityus bahiensis. Chromosome Res. 17: 883-898.

Shanahan CM (1989). Cytogenetics of Australian scorpions. II. Chromosome polymorphism in species of Urodacus (family Scorpionidae). Genome 32: 890-900.

Shultz JW (2007). A phylogenetic analysis of the arachnid orders based on morphological characters. Zool. J. Linn. Soc. 150: 221-265.

Silva EL, Piscor D, Ponzeto JM, Centofante L, et al. (2012). Cytogenetic characterisation of the ornamental freshwater fish, Piabucus melanostomus (Iguanodectinae) from Brazilian wetlands and its relation with species of Characidae basal group. Rev. Fish Biol. Fish. 22: 477-484.

Štáhlavský F and Král J (2004). Karyotype analysis and achiasmatic meiosis in pseudoscorpions of the family Chthoniidae (Arachnida: Pseudoscorpiones). Hereditas 140: 49-60. 
Štáhlavský F, Henderickx H and Král J (2005). Karyotype study on pseudoscorpions of the genus Lasiochernes Beier (Pseudoscorpiones, Chernetidae). Folia Biol. 53: 69-74.

Stávale LM, Schneider MC, Araujo D, Brescovit AD, et al. (2010). Chromosomes of Theridiidae spiders (Entelegynae): Interspecific karyotype diversity in Argyrodes and diploid number intraspecific variability in Nesticodes rufipes. Genet. Mol. Biol. 33: 663-668.

Stávale LM, Schneider MC, Brescovit AD and Cella DM (2011). Chromosomal characteristics and karyotype evolution of Oxyopidae spiders (Araneae, Entelegynae). Genet. Mol. Res. 10: 752-763.

Steinemann M and Steinemann S (1998). Enigma of Y chromosome degeneration: neo-Y and neo-X chromosomes of Drosophila miranda a model for sex chromosome evolution. Genetica 102-103: 409-420.

Sumner AT (1972). A simple technique for demonstrating centromeric heterochromatin. Exp. Cell Res. 75: 304-306.

Suzuki S (1954). Cytological studies in spiders. III. Studies on the chromosomes of fifty-seven species of spiders belonging to seventeen families, with general considerations on chromosomal evolution. J. Sci. Hiroshima Univ. Ser. B 15: 23136.

Tsurusaki N and Cokendolpher JC (1990). Chromosomes of sixteen species of harvestmen (Arachnida, Opiliones, Caddidae and Phalangiidae). J. Arachnol. 18: 151-166.

Vítková M, Král J, Traut W, Zrzavý J, et al. (2005). The evolutionary origin of insect telomeric repeats, (TTAGG). Chromosome Res. 13: 145-156.

Warren E (1939). The genital system of Hypoctonus formosus (Butler) (Thelyphonidae). Ann. Nat. Mus. 9: 307-344.

Weygoldt P (1996). Evolutionary morphology of whip spiders: Towards a phylogenetic system (Chelicerata: Arachnida: Amblypygi). J. Zool. Syst. Evol. Res. 34: 185-202. 